Inflammatory markers in relation to long-term air pollution

Nahid Mostafavi ${ }^{a}$, JelleVlaanderen ${ }^{a}$, Marc Chadeau-Hyam ${ }^{b}$, Rob Beelen ${ }^{a}$, Lars Modig Domenico Palli ${ }^{\mathrm{d}}$, Ingvar Bergdahl ${ }^{\mathrm{c}}$, Paolo Vineis ${ }^{\mathrm{b}, \mathrm{e}}$, Gerard Hoek ${ }^{\mathrm{a}}$, SoteriosA.

\title{
Kyrtopoulos $^{\mathbf{f}}$, Roel Vermeulen ${ }^{\mathrm{a}}$
}

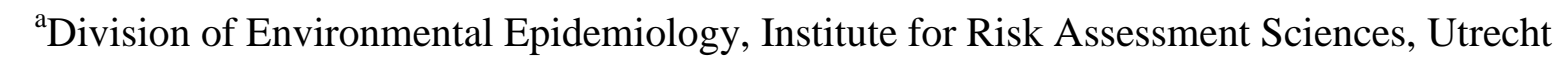

University, 3584 CM, Utrecht, the Netherlands, ${ }^{\mathrm{b}}$ Medical Research Council-Health Protection Agency Centre for Environment and Health, Department of Epidemiology and Biostatistics, Imperial College London, London, United Kingdom, ${ }^{\mathrm{c}}$ Department of Public Health and Clinical Medicine, Occupational and Environmental Medicine, University of Umeå, 901 87,Umeå, Sweden, ${ }^{\mathrm{d}}$ Molecular and Nutritional Epidemiology Unit, Cancer Prevention and Research Institute (ISPO), Florence, Italy, ${ }^{\mathrm{e}} \mathrm{HuGeF}$ Foundation, Turin, Italy, ${ }^{\mathrm{f}}$ National Hellenic Research Foundation, Institute of Biology, Pharmaceutical Chemistry and Biotechnology, Athens, Greece.

E-mail addresses: $\underline{\text { n.s.mostafavimontazeri@uu.nl (Nahid Mostafavi),j.j.Vlaanderen@uu.nl }}$ (Jelle Vlaanderen), m.chadeau@imperial.ac.uk(Marc Chadeau-Hyam), r.m.j.beelen@uu.nl(Rob Beelen), lars.modig@umu.se(Lars Modig), d.palli@ispo.toscana.it (Domenico Palli), ingvar.bergdahl@umu.se (Ingvar Bergdahl),p.vineis@imperial.ac.uk (Paolo Vineis),g.hoek@uu.nl (Gerard Hoek), skyrt@eie.gr (Soterios A. Kyrtopoulos), r.c.h.vermeulen@uu.nl (Roel Vermeulen)

\section{Corresponding author:}

Dr. Roel Vermeulen, Division Environmental Epidemiology, Institute for Risk Assessment Sciences. Yalelaan 2, room 353, 3584 CM, Utrecht, The Netherlands. Tel +31 302539448 (Secr. 9494); Fax +31 30253 9499. E-mail: r.c.h.vermeulen@uu.nl. 
Running title: Air pollution and markers of inflammation

26

Competing interest: The authors declare they have no competing financial interest.

27 


\section{Abstract}

Long-term exposure to ambient air pollution can lead to chronic health effects such as cancer, cardiovascular and respiratory disease. Systemic inflammation has been hypothesized as a putative biological mechanism contributing to these adverse health effects. We evaluated the effect of long-term exposure to air pollution on blood markers of systemic inflammation.

We measured a panel of 28 inflammatory markers in peripheral blood samples from 587 individuals that were biobanked as part of a prospective study. Participants were from Varese and Turin (Italy) and Umea (Sweden). Long-term air pollution estimates of nitrogen oxides $\left(\mathrm{NO}_{\mathrm{x}}\right)$ were available from the European Study of Cohorts for Air Pollution Effects (ESCAPE). Linear mixed models adjusted for potential confounders were applied to assess the association between $\mathrm{NO}_{\mathrm{x}}$ and the markers of inflammation.

Long-term exposure to $\mathrm{NO}_{\mathrm{x}}$ was associated with decreased levels of interleukin (IL)-2, IL-8, IL-10 and tumor necrosis factor- $\alpha$ in Italy, but not in Sweden. $\mathrm{NO}_{\mathrm{x}}$ exposure levels were considerably lower in Sweden than in Italy (Sweden: median $\left(5^{\text {th }}, 95^{\text {th }}\right.$ percentile) $6.65 \mu \mathrm{g} / \mathrm{m}^{3}$; (4.8, 19.7); Italy: median $\left(5^{\text {th }}, 95^{\text {th }}\right.$ percentile) $\left.94.2 \mu \mathrm{g} / \mathrm{m}^{3}(7.8,124.5)\right)$. Combining data from Italy and Sweden we only observed a significant association between long-term exposure to $\mathrm{NO}_{\mathrm{x}}$ and decreased levels of circulating IL-8.

We observed some indication for perturbations in the inflammatory markers due to long-term exposure to $\mathrm{NO}_{\mathrm{x}}$. Effects were stronger in Italy than in Sweden, potentially reflecting the difference in air pollution levels between the two cohorts.

Keywords: Air pollution, inflammatory markers, gene expression, chronic health effects 


\section{Introduction}

Epidemiologic studies have consistently shown an association between long-term exposure to ambient air pollution and cardiovascular mortality and morbidity, non-malignant respiratory diseases (Brunekreef and Holgate 2002; Hoek et al. 2013), and lung cancer (Demetriou et al. 2012). Although the exact mechanisms behind the observed associations are not clear, longterm pulmonary oxidative stress and inflammation induced by chronic exposure to inhaled pollutants has been hypothesized to result in a systemic inflammatory state capable of activating hemostatic pathways, impairing vascular function, and accelerating atherosclerosis (Brook et al. 2010; Rückerl et al. 2007).

The link between the inflammatory process in the lung and the systemic response is thought to be mediated by markers of inflammation released by alveolar macrophage and bronchial epithelial cells in response to exposure to ambient air pollution and capable of entering the systemic circulation and stimulating the production of acute-phase proteins (Demetriou et al. 2012; Hoffman et al. 2009). Inflammatory markers in peripheral blood might therefore reflect deregulation resulting from chronic exposure to ambient air pollution (Dubowsky et al. 2006, van Eeden et al. 2001).

A number of studies have reported on acute changes in blood markers of inflammation in response to day-to-day variability in air pollution. These studies have generally reported inconsistent results. Effects of short-term exposure to ambient air pollutants on the levels of fibrinogen have been reported, either with a negative association (in response to $\mathrm{PM}_{10}$ or $\mathrm{SO}_{2}$ ) (Panasevich et al. 2009; Seaton et al. 1999; Steenhof et al. 2013), or a positive association (in response to $\mathrm{PM}_{10}$ or $\mathrm{O}_{3}$ ) (Rückerl et al. 2007). Short-term exposure to particulate matter has been associated with an increase in IL-6 levels (van Eeden et al. 2001) or shown no relationship (Panasevich et al. 2009; Seaton et al. 1999; Zuurbier and Hoek 2011). A positive 
association with TNF- $\alpha$ levels (in response to $\mathrm{PM}_{10}, \mathrm{NO}_{2}$ ) was reported by (Panasevich et al. 2009; Tsai et al. 2012), but Larsson et al. reported no association with diesel exhaust (Larsson et al. 2013).

We identified four studies that reported on the association between markers of long-term exposure to air pollution and chronic perturbations of blood inflammatory markers (Table S1) (Chuang et al. 2011; Forbes et al. 2009; Hoffman et al. 2009; Panasevich et al. 2009). All studies assessed a small set of blood markers of inflammation. Panasevich et al. (2009) assessed four markers (IL-6, TNF- $\alpha$, CRP, fibrinogen) and reported significantly higher IL-6 levels and positive effect estimates of CRP levels after long term exposure to elevated residential levels of 30-year average traffic-related $\mathrm{NO}_{2}$. Hoffmann et al. (2009) assessed two markers of inflammation (CRP, fibrinogen) and reported a positive association between annual particulate matter $\left(\mathrm{PM}_{2.5}\right)$ and CRP and fibrinogen (an increase of $16.7 \%$ in CRP and 2.4\% in fibrinogen for a unit increase in $\mathrm{PM}_{2.5}$ ). Forbes et al. (2009) also explored the association between estimates of long-term exposure to ambient air pollution and fibrinogen and CRP, but observed no associations. Chuang et al. (2011) assessed two markers of inflammation (IL-6 and neutrophils) and reported that an increase in annual average particulate air pollutant $\left(\mathrm{PM}_{10}\right.$ and $\left.\mathrm{PM}_{2.5}\right)$ and $\mathrm{NO}_{2}$ was marginally $(\mathrm{p}<0.1)$ associated with elevated IL-6 and neutrophils.

We assessed the association between long-term exposure to nitrogen oxides $\left(\mathrm{NO}_{\mathrm{x}}\right)$ and plasma concentration of a large panel of cytokines, chemokines, and growth factors in a sample of the general population. Our study contributes to the existing literature by combining a wide range of inflammatory markers $(\mathrm{n}=28)$ measured in a large number of individuals $(\mathrm{n}=587)$ with state of the art long-term air pollution exposure assessment. By comparing two prospective cohorts from Italy and Sweden, in which we applied the same exposure assessment strategy, we were 
able to study the association over a wide-range of air pollution exposure and assess the between-cohort heterogeneity of our findings. In addition, in a sensitivity analysis, we restricted our analyses to the elderly and the overweight, to assess whether we observed stronger effects among individuals that have been reported to have a higher susceptibility to develop air pollution induced cardiovascular(Bentayeb et al. 2012) and other health effects (Dubowsky et al. 2006; Rückerl et al. 2007; Simoni et al. 2015). 


\section{Materials and methods}

For the current study we combined data from two existing projects: inflammatory markers from Genomics Biomarkers of Environmental Health (EnviroGenoMarkers) (Chadeau-Hyam et al. 2014; Hebels et al. 2013) and $\mathrm{NO}_{\mathrm{x}}$ data from the European Study of Cohorts for Air Pollution Effects (ESCAPE) (Beelen et al. 2013).

\subsection{Study population}

EnviroGenoMarkers was set up to investigate the association between a set of environmental agents (polychlorinated biphenyls, polycyclic aromatic hydrocarbons, cadmium, lead, phthalates, brominated flame retardants, ambient air pollutants and water treatment byproducts), intermediate OMICS markers (metabolomics, epigenomics, proteomics and transcriptomics), and various human diseases (Chadeau-Hyam et al. 2014). It has a nested case-control design, using biosamples of two prospective cohorts: the Italian contribution to the European Prospective Investigation into Cancer and Nutrition study (EPIC-Italy) (Palli et al. 2003), and the Northern Sweden Health and Disease Study (NSHDS) (Hallmans et al. 2003). EPIC-Italy was initiated in 1992 and completed the recruitment of 15,171 men and 32,578 women healthy middle-aged (35-70 years old) volunteers in 4 different areas of Italy: Varese, Turin, Ragusa, and Florence (Palli et al. 2003). The NSHDS cohort contains 3 subcohorts: the Västerbotten Intervention program (VIP), the Västerbotten Mammary Screening (MS) Program and the Northern Sweden MONICA project. It started in 1985 and the total cohort and biobank contains at present 85,000 unique healthy individuals (Hallmans et al. 2003). At the time of recruitment (around 2002), cohort members from both studies completed a standardized questionnaire focusing on dietary and life-style habits and donated blood. 
The EnviroGenoMarkers data included in the current study were collected in two phases. In the first phase 100 Non-Hodgkin's lymphoma cases, 100 breast cancer cases, were identified through local Cancer Registries (loss to follow-up < 2\%) and occurred on average 6 years (range 1 to 17 years) after recruitment/blood collection, and the same number of controls matched on sex, age, center and date of blood collection were included (Chadeau-Hyam et al. 2014). The lymphoma case-control data were subsequently supplemented with samples from additional cases (147 cases in NSHDS, 34 cases in EPIC-Italy) and equal number of similarly matched controls (phase 2) (Chadeau-Hyam et al. 2014; Kelly et al. 2013).

Our study population, a subset of the EnviroGenoMarkers data, includes 97 individuals (23 men, and 74 women) from two centers participating in the EPIC-Italy cohort (Turin and Varese) and 490 individuals (210 men, and 280 women) from the NSHDS cohort (Umeå). Our selection from the NSHDS cohort includes 195 future Non-Hodgkin's lymphoma cases (49 from phase 1 and 146 from phase 2), 50 future breast cancer cases, and 245 controls matched on sex, age, center and date of blood collection. Our selection from the EPIC-Italy cohort includes 38 future Non-Hodgkin's lymphoma cases (24 from phase 1 and 14 from phase 2), 12 future breast cancer cases, and 47 controls matched on sex, age, center and date of blood collection. The average time to diagnosis for breast cancer cases was 6 years (range 2 to 10 years) and for lymphoma cases was 6 years (range 2 to 16 years) after blood collection.

\subsection{Cytokine measurements}

Plasma levels of a panel of 28 inflammatory markers including interleukin (IL) 1 1 , IL-2, IL-4, IL-5, IL-6, IL-7, IL-8, IL-10, IL-12, IL-13, interferon alpha (INF- $\alpha$ ), interferon gamma (INF$\gamma$ ), tumor necrosis factor alpha (TNF- $\alpha$ ), eotaxin, IL1 receptor antagonist (IL1ra), interferon gamma-induced protein 10 (IP10), granulocyte-macrophage colony-stimulating factor (GMCSF), epidermal growth factor (EGF), fibroblast growth factor 2 (FGF2), fms-like tyrosine kinase receptor-3 (Flt3) ligand protein (Flt3 ligand), granulocyte colony-stimulating 
factor (GCSF), melanoma growth stimulatory activity/growth-related oncogene (GRO), monocyte chemotactic protein-1 (MCP-1), monocyte chemotactic protein-3 (MCP-3), macrophage derived chemokine (MDC), macrophage inflammatory protein-1 alpha (MIP-1 $\alpha$ ), macrophage inflammatory protein-1 beta (MIP-1ß), soluble CD40 ligand (sCD40L), soluble IL-2 receptor alpha $(\operatorname{sIL} 2 \mathrm{R} \alpha)$, transforming growth factor alpha (TGF- $\alpha)$, and vascular endothelial growth factor (VEGF) were measured in stored samples of all subjects using the milliplex hcytomag-60 19.Hum and hcytomag-60SPMX13 kits, according to the protocol described by the manufacturer (Saberi Hosnijeh et al. 2012). Quality control samples were run in duplicate with the study samples in each batch (Saberi Hosnijeh et al. 2010).

Samples from EPIC-Italy contained citrate as anticoagulant and had been stored in cryostraws in liquid nitrogen for 11-19 years. Their recorded collection-to-storage times were 55-347 min. Samples from NSHDS contained heparin or EDTA as anticoagulant and had been stored in plastic cryovials at $-80 \mathrm{C}$ for $4-19$ years. Blood samples were generally collected in the morning and their collection-to-storage time was always $<1$ hour (Hebels et al. 2013). A previous analysis showed that samples not cold-stored within $2 \mathrm{~h}$ after blood collection had significantly different expression profiles than fresh samples, and therefore only peripheral blood mononuclear cells samples that had been placed in cold storage within $2 \mathrm{~h}$ after blood collection were included in the current study (Chadeau-Hyam et al. 2014).

\subsection{Exposure assessment}

The European Study of Cohorts for Air Pollution Effects (ESCAPE) study was set up to investigate the effect of long-term exposure to ambient air pollution on human health in 15 European countries (Beelen et al. 2013; Cyrys et al. 2012). ESCAPE measurements, includes 36 cohorts which study areas cover Europe. Exposure levels were estimated using land use regression models that were developed using exposure measurements conducted between October 2008 and April 2011 (Beelen et al. 2013). Study area specific land use regression 
models were used to assign estimates of long-term exposure to the cohort participants homeaddress. Land use regression models were developed combining exposure measurements conducted at a restricted number of sites (40 to 80 ) covering each study area with Geographic Information System (GIS) based predictors. Exposure to nitrogen oxides $\left(\mathrm{NO}_{2}\right.$ and $\left.\mathrm{NO}_{\mathrm{x}}\right)$ was assessed for all study areas participating in ESCAPE, while exposure to particulate matter $\left(\mathrm{PM}_{2.5}, \mathrm{PM}_{2.5}\right.$ absorbance and $\left.\mathrm{PM}_{10}\right)$ was assessed for a subset of study areas that contributed to the contrast in exposure in the ESCAPE dataset. Of the three study areas that were included in EnviroGenoMarkers (Umeå, Turin, and Varese) particulate matter estimates were only available for 13 subjects from Turin (Beelen et al. 2013). We therefore based our analyses on $\mathrm{NO}_{\mathrm{x}}$. In the cities included in the current analysis the squared correlations $\left(\mathrm{R}^{2}\right)$ between $\mathrm{NO}_{\mathrm{x}}$ and $\mathrm{NO}_{2}$ ranged between 0.94 and 0.97 . The $\mathrm{NO}_{2} / \mathrm{NO}_{\mathrm{x}}$ ratio was $0.57,0.54,0.53$ for Umea, Turin, Varese areas, respectively (Cyrys et al. 2012).

\subsection{Data analysis}

For four markers of inflammation (IL-12, IL1-RA, sIL2-RA, and Flt3 ligand) more than 50\% of the samples were below the limit of detection (LOD). We excluded these markers from our analyses. Data were imputed when measurements were out of range of the calibration curve (either too low: $<\mathrm{LOD}$, or too high) based on a maximum likelihood estimation procedure (Lubin et al. 2004). For imputation of samples <LOD we imputed using the empirical LOD across all plates as the upper bound. For imputation of samples with a concentration exceeding the calibration curve we used a value of the twice the highest observed concentration that was not out of range as the upper bound. Among the analytes that were retained, the maximum percentage of imputed values was $47.7 \%$ (IL-13), while $70 \%$ of the retained markers had less than $30 \%$ imputed values.

For six individuals in the Varese population unrealistically low $\mathrm{NO}_{\mathrm{x}}$ exposure estimates $\left(<0.16 \mu \mathrm{g} / \mathrm{m}^{3}\right)$ were predicted by the ESCAPE model. We set these values at the $2.5^{\text {th }}$ 
percentile of the distribution of $\mathrm{NO}_{\mathrm{x}}$ exposure estimates in the full Varese study population also including individuals for which markers of inflammation were not assessed $\left(7.81 \mu \mathrm{g} / \mathrm{m}^{3}\right)$. We assessed the sensitivity of this decision by replacing the $2.5^{\text {th }}$ percentile by either the $1.5^{\text {th }}$ or the $5^{\text {th }}$ percentile of the distribution and observed that our results were robust.

We conducted linear mixed-effects modeling to investigate the association between long-term exposure to $\mathrm{NO}_{\mathrm{x}}$ and markers of inflammation. We included random intercepts for microtiter plate in the model to capture nuisance variation generated in the assessment of the inflammatory markers (clustering of the inflammatory markers measurements by plate) (McHale et al. 2011) and included fixed-effects for $\mathrm{NO}_{\mathrm{x}}$ and for a priori selected potential confounding factors, i.e., body mass index (BMI) $\left(\mathrm{kg} / \mathrm{m}^{2}\right)$, age (in three categories: $(30,40]$, $(40,50],(50,75]$, years), sex (female, male), smoking status (never, former, current), phase (1 and 2), future disease status (lymphoma case, breast cancer case, control) and sample storage time (years) consistent with previous analyses of the EnviroGenoMarkers data (ChadeauHyam et al. 2014; Kelly et al. 2013). As a sensitivity analysis, we explored the potential for confounding by the remaining factors available in our dataset including socio-economic status (education level (primary, technical, secondary, university)), and physical activity (moderately inactive, moderately active, active).

Due to differences in dietary habits, lifestyle, and air pollution exposure levels between the Italian and Swedish cohorts, we stratified our analyses by cohort (Table 1; Figure 1). As there was some overlap in the exposure distributions of the two cohorts, we also conducted analyses on the combined cohorts, while adjusting for country (Figure 1).

As sensitivity analysis we explored the association between $\mathrm{NO}_{\mathrm{x}}$ and markers of inflammation in two potentially susceptible strata: among overweight individuals (BMI>25; n=323) and among individuals older than age 50; $\mathrm{n}=383$. In addition, we performed analyses among never 
smokers $(n=353)$ to assess the effect of potential residual confounding by active smoking, and among controls only $(n=292)$ to assess the effect of potential bias due to early manifestations of future disease.

We natural $\log$ transformed $\mathrm{NO}_{\mathrm{x}}$ and markers of inflammation to limit the influence of high concentrations and normalize distributions. We computed unadjusted p-values and adjusted pvalues for multiple testing (q values) by controlling the false discovery rate (FDR) at $5 \%$. We used penalized splines ( $\mathrm{P}$-spline) in the generalized additive mixed-model (GAMM) framework to assess potential non-linearity of the relationships between inflammatory markers and exposure.

Correlation coefficients between all markers of inflammation were assessed using Pearson correlation. A two-sided q-value $<0.05$ was considered statistically significant. Statistical analyses were performed using $\mathrm{R}$ version 3.0.2 (package lme4). 


\section{Results}

We summarized the general characteristics of the study population by cohort in Table 1 . The Swedish cohort had a lower proportion of women than the Italian cohort (57\% versus $76 \%$ ), a higher proportion of current smokers (21\% versus $8 \%$ ) and a lower proportion of never smokers (59\% versus $66 \%$ ). We observed a considerable difference in the distribution of $\mathrm{NO}_{\mathrm{x}}$ concentrations between the two cohorts (Table 1; Figure 1). The median $\left(5^{\text {th }}, 95^{\text {th }}\right)$ concentration of $\mathrm{NO}_{\mathrm{x}}$ estimated for the Italian cohort $\left(94.2 \mu \mathrm{g} / \mathrm{m}^{3}(7.8,124.5)\right)$ was considerably higher than the median concentration estimated for the Swedish cohort $(6.65$ $\left.\mu \mathrm{g} / \mathrm{m}^{3}(4.8,19.7)\right)(\mathrm{p}<0.001)$.

Univariate mixed-effect regression analyses yielded evidence for an association between long-term exposure to $\mathrm{NO}_{\mathrm{x}}$ and several markers of inflammation. In Table 2 we report the significant effects and in Table $\mathrm{S} 2$ we report the results for the complete set of inflammatory markers. Our strongest finding is for IL-8, for which we observed a significant negative association in the Italian cohort as well as in the combined cohort (q-values of 0.001 and 0.02 , respectively). For an inter quartile change in NOx concentration in the combined cohort (10 $\left.\mu \mathrm{g} / \mathrm{m}^{3}\right)$ IL-8 decreased $5.1 \mathrm{pg} / \mathrm{mL}$ (17\% decrease). Although a negative association between $\mathrm{NO}_{\mathrm{x}}$ and IL-8 was observed in the Swedish cohort as well, this association was not significant $(q=0.655)$. For several other markers we observed significant negative associations with long-term exposure to $\mathrm{NO}_{\mathrm{x}}$ in the Italian cohort, but not in the Swedish or combined cohorts: IL-2 $(q=0.012)$, TNF- $\alpha(q=0.020)$, IL-10 $(q=0.017)$. For IL-10 the non-significant association observed in the combined cohorts was in the same direction as it was in the Italian cohort (q 0.083). 
We observed little influence of the potential confounding factors on the effect of $\mathrm{NO}_{\mathrm{x}}$ on the markers of inflammation (the effect size did not change after adjustment for the potential confounding factors).

Results from sensitivity analyses among never-smokers (Table 3 for the significant effects and Table S3 for the complete set of markers) and among controls only (see supplemental material, Table S7) were similar, though with larger standard errors, compared to the results from our main analyses, suggesting limited impact of potential residual confounding of smoking or future (lymphoma or breast cancer) case status. We assessed the impact on our results of additional correction for further covariates available in the EnviroGenoMarkers dataset, but observed no considerable changes in effect estimates $(<5 \%$ for the markers of inflammation for which we observed a significant association with $\mathrm{NO}_{\mathrm{x}}$; results not shown). We did not observe any evidence for deviation from linearity for the markers significantly associated with $\mathrm{NO}_{\mathrm{x}}$ at the $\log$ scale (results not shown).

The associations between $\mathrm{NO}_{\mathrm{x}}$ and the inflammatory markers within different subgroups of the combined population are presented in Table 3 (cohort-specific results are presented in supplemental material, Tables S4, S5, and S6). In the stratified model, the size of the effect of $\mathrm{NO}_{\mathrm{x}}$ on several inflammatory markers (especially IL-8) was often larger in overweight individuals than in non-overweight individuals. We observed smaller effect sizes of $\mathrm{NO}_{\mathrm{x}}$ on the markers of inflammation among elderly individuals. However, we did not observe a significant interaction between $\mathrm{NO}_{\mathrm{x}}$ and $\mathrm{BMI}$ or age in the unstratified models. 
Table 1. Descriptive characteristics of the study population

\begin{tabular}{|c|c|c|}
\hline \multirow[t]{2}{*}{ Characteristics } & \multicolumn{2}{|c|}{ N $(\%)$ or Mean/Median $\left(\mathrm{SD}^{\mathbf{a}}\right)$} \\
\hline & Swedish cohort $(n=490)$ & Italian cohort $(n=97)$ \\
\hline \multicolumn{3}{|l|}{$\operatorname{Sex}(\mathbf{N}(\%))$} \\
\hline Female & $280(57 \%)$ & $74(76 \%)$ \\
\hline Male & $210(43 \%)$ & $23(24 \%)$ \\
\hline \multicolumn{3}{|l|}{ Smoking Status (N (\%)) } \\
\hline Current- smoker & $104(21 \%)$ & $8(8 \%)$ \\
\hline Former- smoker & $97(20 \%)$ & $25(26 \%)$ \\
\hline Never-smoker & $289(59 \%)$ & $64(66 \%)$ \\
\hline \multicolumn{3}{|l|}{ Age $($ years $)(\mathbf{N}(\%))$} \\
\hline$<40$ & $29(6 \%)$ & $2(2 \%)$ \\
\hline $40-50$ & $143(29 \%)$ & $30(31 \%)$ \\
\hline$>\mathbf{5 0}$ & $318(65 \%)$ & $65(67 \%)$ \\
\hline $\operatorname{BMI}^{\mathrm{b}}\left(\mathrm{kg} / \mathrm{m}^{2}\right)\left(\right.$ Mean $\left.\pm \mathrm{SD}^{*}\right)$ & $26.1 \pm 4.1$ & $25.7(3.8)$ \\
\hline $\mathrm{NO}_{\mathrm{x}}^{\mathrm{c}}\left(\mu \mathrm{g} / \mathrm{m}^{3}\right)\left(\operatorname{Median}\left(\mathrm{SD}^{*}\right)\right.$ & $6.65(5.84)$ & $94.2(42.4)$ \\
\hline
\end{tabular}




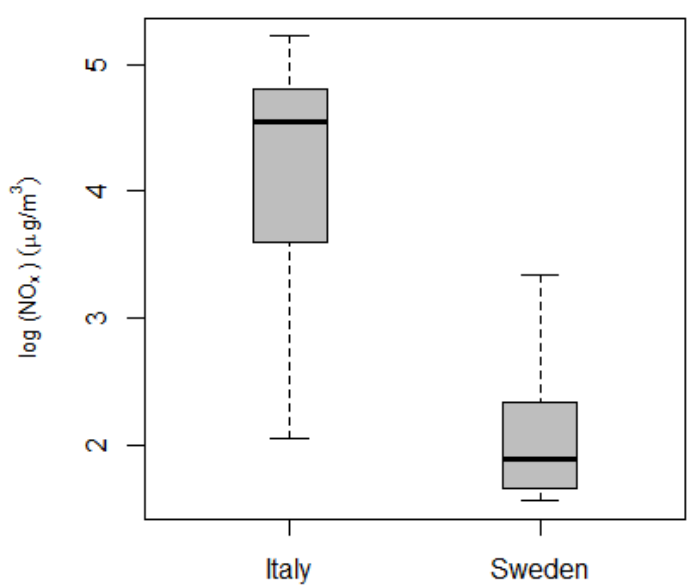

286

287 Fig1. Box plot (left) and density plot (right) of $\log \left(\mathrm{NO}_{\mathrm{x}}\right)\left(\mu \mathrm{g} / \mathrm{m}^{3}\right)$ exposure levels

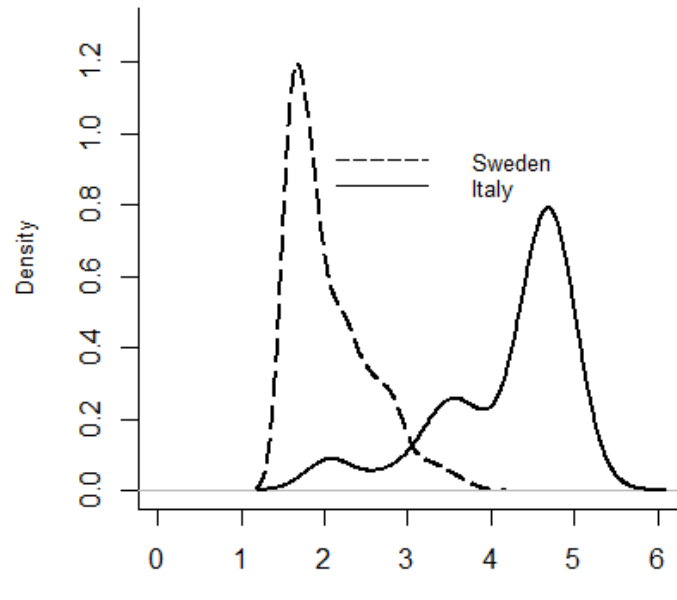

$\log \left(\mathrm{NO}_{\mathrm{x}}\right)\left(\mu \mathrm{g} / \mathrm{m}^{3}\right)$ observed in the Swedish and Italian cohorts. 


\section{adjusted for potential confounders}

\begin{tabular}{|c|c|c|c|c|c|c|c|c|c|c|c|c|}
\hline \multirow[b]{2}{*}{$\begin{array}{c}\text { Inflammatory } \\
\text { markers }\end{array}$} & \multicolumn{4}{|c|}{ Combined cohort $(n=587)$} & \multicolumn{4}{|c|}{ Swedish cohort $(n=490)$} & \multicolumn{4}{|c|}{ Italian cohort $(n=97)$} \\
\hline & $\beta^{e}$ & $\mathrm{SE}^{\mathrm{a}}$ & P-Value & Q-Value ${ }^{b}$ & $\beta$ & SE & P-Value & Q-Value & $\beta$ & SE & P-Value & Q-Value \\
\hline $\mathrm{IL}^{\mathrm{c}}-2$ & -0.058 & 0.118 & 0.623 & 0.703 & -0.019 & 0.144 & 0.896 & 0.896 & -0.421 & 0.143 & 0.003 & 0.012 \\
\hline IL-8 & -0.179 & 0.068 & 0.008 & 0.020 & -0.079 & 0.076 & 0.295 & 0.655 & -0.520 & 0.133 & 0.000 & 0.001 \\
\hline IL-10 & -0.256 & 0.116 & 0.028 & 0.083 & -0.104 & 0.142 & 0.467 & 0.619 & -0.690 & 0.218 & 0.002 & 0.017 \\
\hline $\mathrm{TNF}^{\mathrm{d}}-\alpha$ & -0.028 & 0.057 & 0.620 & 0.643 & 0.036 & 0.073 & 0.625 & 0.689 & -0.213 & 0.069 & 0.002 & 0.020 \\
\hline
\end{tabular}

292

293

294

295

296

297

298

299

300

301
${ }^{\mathrm{a}} \mathrm{SE}$, standard error of $\beta ;{ }^{\mathrm{b}} \mathrm{Q}-$ Value, False Discovery Rate correction for P-Value, ${ }^{\mathrm{c}}$ Interleukin (IL), and ${ }^{\mathrm{d}}$ tumor necrosis factor alpha (TNF- $\alpha$ ), ${ }^{\mathrm{e}}$ effect estimate per unit changes of the exposure

Results are based on linear mixed-effects models of log-transformed dependent and independent variables with fixed-effects: body mass index (BMI) $\left(\mathrm{kg} / \mathrm{m}^{2}\right)$, age (years), sex (female, male), smoking status (never, former, current), phase (1 and 2), future disease status (lymphoma case, breast cancer case, control) and sample storage time (years). And plate as random effects. 
Table3. Significant effects of long-term exposure to $\mathrm{NO}_{\mathrm{x}}$ on markers of inflammation

within 3 sub-groups (overweight, elderly, and never-smokers)

\begin{tabular}{|c|c|c|c|c|c|c|c|c|c|c|c|c|}
\hline \multirow{2}{*}{$\begin{array}{l}\text { Inflammatory } \\
\text { markers }\end{array}$} & \multicolumn{4}{|c|}{ Overweight (n=323) } & \multicolumn{4}{|c|}{ Elderly $(n=383)$} & \multicolumn{4}{|c|}{ Never-smokers $(n=353)$} \\
\hline & $\beta^{e}$ & $\mathrm{SE}^{\mathrm{a}}$ & P-Value & Q-Value ${ }^{b}$ & $\beta$ & SE & P-Value & Q-Value & $\beta$ & SE & P-Value & Q-Value \\
\hline $\mathrm{IL}^{\mathrm{c}}-2$ & -0.073 & 0.144 & 0.613 & 0.843 & -0.080 & 0.139 & 0.566 & 0.778 & 0.104 & 0.154 & 0.502 & 0.628 \\
\hline IL-8 & -0.254 & 0.078 & 0.001 & 0.004 & -0.039 & 0.078 & 0.619 & 0.847 & -0.113 & 0.093 & 0.226 & 0.282 \\
\hline IL-10 & -0.270 & 0.131 & 0.040 & 0.073 & -0.301 & 0.135 & 0.026 & 0.071 & -0.180 & 0.160 & 0.262 & 0.427 \\
\hline $\mathrm{TNF}^{\mathrm{d}}-\alpha$ & 0.032 & 0.067 & 0.629 & 0.766 & 0.012 & 0.069 & 0.866 & 0.951 & 0.017 & 0.068 & 0.803 & 0.882 \\
\hline
\end{tabular}

304

$305{ }^{\mathrm{a}} \mathrm{SE}$, standard error of $\beta ;{ }^{\mathrm{b}} \mathrm{Q}-$ Value, False Discovery Rate correction for P-Value, ${ }^{\mathrm{c}}$ Interleukin

306 (IL), and ${ }^{\mathrm{d}}$ tumor necrosis factor alpha (TNF- $\left.\alpha\right)$, ${ }^{\mathrm{e}}$ effect estimate per unit changes of the

307 exposure

308 Results are based on linear mixed-effects models of log-transformed dependent and

309 independent variables. Sex (female, male), phase (1 and 2), future disease status (lymphoma

310 case, breast cancer case, control) and sample storage time (years) were included as fixed

311 effects and plate as random effect. 


\section{Discussion}

This study provides some evidence for a perturbation of systemic inflammatory markers due to long-term exposure to $\mathrm{NO}_{\mathrm{x}}$ in a cohort of healthy Italian and Swedish individuals. We observed significantly decreased levels of IL-8 in the combined cohort and for three other inflammatory markers in the Italian sub-cohort, but observed no evidence for any association in the Swedish sub-cohort.

Our finding of an inverse association between long-term exposure to air pollution and IL-2, IL-8, IL-10, and TNF- $\alpha$ is in contrast to results from most previous studies of long-term exposure to air pollution and markers of inflammation, which have generally reported positive associations (Hofmann et al. 2011; Panasevich et al. 2009). Similarly, studies focused on the biological mechanisms of these markers of inflammation have reported a primarily proinflammatory role. We summarize the current knowledge below. IL-2 performs critical functions for the elimination of diseased cells, including promotion of $\mathrm{T}$ and natural killer (NK) cells, cytolytic activities, and regulation of naive T cell differentiation into Th1 and Th2 subsets upon exposure to antigens (Liao et al. 2013). IL-8 is produced under inflammation stimulation and is attracting and activating neutrophilic granulocytes (Zarogoulidis et al. 2014). TNF- $\alpha$ is involved in the innate immune response (Clark 2007). IL-10 is an immunoregulatory cytokine mainly secreted by macrophages, but also by T helper 1 (Th1) and Th2 lymphocytes, dendritic cells, cytotoxic T cells, B lymphocytes, monocytes and mast cells. IL-10 inhibits the capacity of monocytes and macrophages to present antigen to $\mathrm{T}$ cells and therefore downregulates the expression of IL-1 $\beta$, IL- 6 , IL-8, IL-12 and TNF- $\alpha$ (Trifunović et al. 2015). Although we do observe downregulation of IL-8 and TNF- $\alpha$ in our study, this finding does not correspond to the observation that IL-10 is downregulated as well.

Interestingly, a study by Forbes et al. (2009) also observed negative associations between long-term exposure to air pollution and markers of inflammation (fibrinogen and C-reactive 
protein), triggering Forbes et al. (2009) to hypothesize that the health effects of chronic outdoor air pollution are not mediated by systemic inflammation. Some short-term air pollution studies have also reported inverse associations with selected markers of inflammation (e.g. (Seaton et al. 1999) (Fibrinogen), and (Rückerl et al. 2007), (IL-6)). Reasons for these inverse associations remain unclear. Furthermore, similar inverse patterns have been observed in relation to other exposures such as endotoxin (Lauw et al. 2000) and carbon monoxide (Morse et al. 2003) and can be seen as indicative of a de-regulation of the inflammatory system.

Our study was subject to some (potential) limitations. One potential limitation is related to the air pollution exposure metric we used in our analyses, as only $\mathrm{NO}_{\mathrm{x}}$ exposure estimates were available. Although the correlation of spatial variation in $\mathrm{NO}_{\mathrm{x}}$ and particulate matter is often high (and was high ( $\rho$ 0.83) in the ESCAPE study from which we derived our exposure estimates (Eeftens et al. 2012)), generally stronger associations with chronic health effects have been observed for particulate matter (especially $\mathrm{PM}_{2.5}$ ) than for $\mathrm{NO}_{\mathrm{x}}$ (Beelen et al. 2014) and particulate matter has been suggested to be a better marker for ambient air pollution than $\mathrm{NO}_{\mathrm{x}}$ (Hoek et al. 2013). Another limitation of our exposure metric, related to the design of ESCAPE, is the fact that current exposure levels were used to assign exposure for historical home addresses (in some cases more than 20 years retrospectively), which might have introduced a certain degree of measurement error. However, several studies have documented that the land use regression models can be applied successfully to estimate air pollution concentrations several years forwards or backwards in time. Although the absolute level of exposure to air pollution has generally decreased over time, spatial contrasts for $\mathrm{NO}_{2}$ have been shown to remain stable over long periods of time (10 years and longer) (Cesaroni et al. 2012; Gulliver et al. 2013; Wang et al. 2013; Eeftens et al. 2011). Note, we performed a sensitivity analyses within the Swedish part of the study using back-extrapolated NOx 
exposure levels at time of the blood draw using the methodology described in (Beelen et al. 2014). Results of these analyses did not provide any different results. The markers of inflammation that we included in our analysis are subject to variability over time (e.g. diurnal and seasonal variation), likely contributing to increased standard errors (Forbes et al. 2009). Several studies have shown examples of considerably larger between-person variability in markers of inflammation than within-person variability, suggesting that single measurements of circulating inflammatory markers provide information about long-term perturbation of the inflammatory markers (Hofmann et al. 2011; Navarro et al. 2012).

Due to the nested case-control design of the EnviroGenoMarkers study our study population included future cancer cases (individuals that were diagnosed with lymphoma or breast cancer in the years following biological sampling) and matched controls. A potential implication of this design for our study is a perturbation of the inflammatory markers due to pre-diagnostic manifestation of the disease among cases. However our results did not change significantly when we restricted our analyses to controls only. In addition, the fact that our study population cannot be viewed as a random sample from the general population might have reduced the external validity of our findings (but should not have any impact on the internal validity).

We observed stronger associations in the Italian cohort than in the Swedish cohort. Although the exposure assessment strategy in both cohorts was the same, the cohorts differed with regards to certain aspects. The difference in the air pollution exposure level between the two cohorts likely contributed considerably to the level of statistical significance (but not the direction) of the observed association. Although most of the individuals in our analyses were included from the Swedish cohort, absolute exposure levels and the exposure contrast in that cohort were low (median $6.65 \mu \mathrm{g} / \mathrm{m}^{3}$, SD 5.8), compared to the Italian cohort (median 94.21 $\mu \mathrm{g} / \mathrm{m}^{3}, \mathrm{SD} 43.0$ ). Furthermore $\mathrm{NO}_{\mathrm{x}}$ exposure levels observed in the Swedish cohort were the 
lowest observed among the 36 European regions for which exposure to $\mathrm{NO}_{\mathrm{x}}$ was estimated in the ESCAPE study, while exposure levels observed for the Italian cohort (especially the Turin cohort) were among the highest (Cyrys et al. 2012). If we restricted the analyses of the Swedish cohort to subjects exposed to $\mathrm{NO}_{\mathrm{x}}$ levels higher than the lowest $5^{\text {th }}$ percentile $(7.8$ $\mu \mathrm{g} / \mathrm{m}^{3}$ ) of the Italian cohort, we did not observe a more homogeneous picture.

Differences between the cohorts also existed with regards to age, sex, BMI, and smoking behavior. As we controlled for these aspects in our analyses, a large impact on our results is unlikely. Further (not a priori selected) factors available in our dataset including, socioeconomic status, dietary patterns, and physical activity, did not significantly explain variability in markers of inflammation within the two cohorts independently and are therefore unlikely responsible for the observed differences between the cohorts. The cohorts differed with regards to the anticoagulant that was used in the blood samples (EDTA in Sweden, citrate in Italy). Although the use of different anticoagulants results in absolute differences in levels of inflammatory markers (See Table S8 for the variance of the concentration of each inflammation marker for the Swedish and Italian cohorts separately), correlations between measurements in split samples simultaneously treated with heparin, citrate, and EDTA have shown to be highly correlated (Hebels et al. 2013; Wong et al. 2008). The difference between the Swedish and the Italian cohort with respect to the anticoagulant that was used, for which we corrected in the statistical models on the combined dataset by adjusting for cohort, is therefore an unlikely explanation for the observed between-cohort differences in our results.

Our analysis among two groups of potentially susceptible populations (individuals with a BMI > 25 or individuals older than age 50) provided some indication (though not significant) for a larger effect among the overweight, but not among the individuals older than age 50. As individuals with conditions associated with chronic inflammation such as older or overweight individuals have been shown to have enhanced susceptibility for air pollution related health 
effects (Dubowsky et al. 2006; Rückerl et al. 2007), we a-priori assumed a larger effect size in these subgroups compared to the overall population. For the overweight this was indeed the case. However, among the elderly we observed a smaller effect size compared to the effect size observed in the overall population. Considering the unexpected inverse relationship that we observed between exposure to air pollution and cytokine production, further biological interpretation of these patterns in the effect sizes is not evident.

\section{Conclusion}

Our results suggested some indication of an inverse association between long-term $\mathrm{NO}_{\mathrm{x}}$ exposure and four systemic inflammatory markers: IL-2, IL-8, IL10, and TNF- $\alpha$. These results might contribute to a future elucidation of the pathways through which long term exposure to air pollution induces adverse health effects.

\section{Acknowledgements:}

The research leading to these results has received funding from the European Community's Seventh Framework Program (FP7/2007e2011) under grant agreement number: 211250 (the European Study of Cohorts for Air Pollution Effects), 226756, (Envirogenomarkers), and 308610 (Exposomics).

We thank all those who are responsible for data management in both the European Study of Cohorts for Air Pollution Effects and EnviroGenoMarkers cohorts. 


\section{References}

Beelen R, Hoek G, Vienneau D, Eeftens M, Dimakopoulou K, Pedeli X, et al. 2013. Development of NO2 and NOx land use regression models for estimating air pollution exposure in 36 study areas in Europe - The ESCAPE project. Atmos. Environ. 72:10-23; doi:10.1016/j.atmosenv.2013.02.037.

Beelen R, Raaschou-Nielsen O, Stafoggia M, Andersen ZJ, Weinmayr G, Hoffmann B, et al. 2014. Effects of long-term exposure to air pollution on natural-cause mortality: an analysis of 22 European cohorts within the multicentre ESCAPE project. Lancet 383:785-95; doi:10.1016/S0140-6736(13)62158-3.

Bentayeb M, Simoni M, Baiz N, Norback D, Baldacci S, Maio S, et al. 2012. Adverse respiratory effects of outdoor air pollution in the elderly. Int. J. Tuberc. Lung Dis. 16:1149-1161; doi:10.3978/j.issn.2072-1439.2014.12.10.

Brook RD, Rajagopalan S, Pope CA, Brook JR, Bhatnagar A, Diez-Roux A V, et al. 2010. Particulate matter air pollution and cardiovascular disease: An update to the scientific statement from the American Heart Association. Circulation 121:2331-78; doi:10.1161/CIR.0b013e3181dbece1.

Brunekreef B, Holgate ST. 2002. Air pollution and health. Lancet 360:1233-42; doi:10.1016/S0140-6736(02)11274-8.

Cesaroni G, Porta D, Badaloni C, Stafoggia M, Eeftens M, Meliefste K, et al. 2012. Nitrogen dioxide levels estimated from land use regression models several years apart and association with mortality in a large cohort study. Environ. Health 11:48; doi:10.1186/1476-069X-11-48.

Chadeau-Hyam M, Vermeulen RCH, Hebels DG a J, Castagné R, Campanella G, Portengen L, et al. 2014. Prediagnostic transcriptomic markers of Chronic lymphocytic leukemia reveal perturbations 10 years before diagnosis. Ann. Oncol. 1-8; doi:10.1093/annonc/mdu056.

Chuang K-J, Yan Y-H, Chiu S-Y, Cheng T-J. 2011. Long-term air pollution exposure and risk factors for cardiovascular diseases among the elderly in Taiwan. Occup. Environ. Med. 68:64-8; doi:10.1136/oem.2009.052704.

Clark I a. 2007. How TNF was recognized as a key mechanism of disease. Cytokine Growth Factor Rev. 18:335-43; doi:10.1016/j.cytogfr.2007.04.002.

Cyrys J, Eeftens M, Heinrich J, Ampe C, Armengaud A, Beelen R, et al. 2012. Variation of NO2 and NOx concentrations between and within 36 European study areas: Results from the ESCAPE study. Atmos. Environ. 62:374-390; doi:10.1016/j.atmosenv.2012.07.080.

Demetriou C a, Raaschou-Nielsen O, Loft S, Møller P, Vermeulen R, Palli D, et al. 2012. Biomarkers of ambient air pollution and lung cancer: a systematic review. Occup. Environ. Med. 69:619-27; doi:10.1136/oemed-2011-100566. 
Dubowsky SD, Suh H, Schwartz J, Coull BA, Gold DR. 2006. Diabetes, obesity, and hypertension may enhance associations between air pollution and markers of systemic inflammation. Environ. Health Perspect. 114: 992-8.

Eeftens M, Beelen R, Fischer P, Brunekreef B, Meliefste K, Hoek G. 2011. Stability of measured and modelled spatial contrasts in NO2 over time. Occup. Environ. Med. 68:765-770; doi:10.1136/oem.2010.061135.

Eeftens M, Tsai M-Y, Ampe C, Anwander B, Beelen R, Bellander T, et al. 2012. Spatial variation of PM2.5, PM10, PM2.5 absorbance and PMcoarse concentrations between and within 20 European study areas and the relationship with NO2 - Results of the ESCAPE project. Atmos. Environ. 62:303-317; doi:10.1016/j.atmosenv.2012.08.038.

Forbes LJL, Patel MD, Rudnicka AR, Cook DG, Bush T, Stedman JR, et al. 2009. Chronic exposure to outdoor air pollution and markers of systemic inflammation. Epidemiology 20:245-53; doi:10.1097/EDE.0b013e318190ea3f.

Gulliver J, de Hoogh K, Hansell A, Vienneau D. 2013. Development and back-extrapolation of NO2 land use regression models for historic exposure assessment in Great Britain. Environ. Sci. Technol. 47:7804-11; doi:10.1021/es4008849.

Hallmans G, Agren A, Johansson G, Johansson A, Stegmayr B, Jansson J-H, et al. 2003. Cardiovascular disease and diabetes in the Northern Sweden Health and Disease Study Cohort - evaluation of risk factors and their interactions. Scand. J. Public Health. Suppl. 61:18-24; doi:10.1080/14034950310001432.

Hebels DG a J, Georgiadis P, Keun HC, Athersuch TJ, Vineis P, Vermeulen R, et al. 2013. Performance in omics analyses of blood samples in long-term storage: opportunities for the exploitation of existing biobanks in environmental health research. Environ. Health Perspect. 121:480-7; doi:10.1289/ehp.1205657.

Hoek G, Krishnan RM, Beelen R, Peters A, Ostro B, Brunekreef B, et al. 2013. Long-term air pollution exposure and cardio- respiratory mortality: a review. Environ. Health 12:43; doi:10.1186/1476-069X-12-43.

Hoffman B, Moebus S, Dragano N, Stang A, Möhlenkamp S, Schmermund A, et al. 2009. Chronic Residential Exposure to Particulate Matter Air Pollution and Systemic Inflammatory Markers. Environ. Health Perspect. 117:1302; doi:10.1289/ehp.0800362.

Hofmann JN, Yu K, Bagni RK, Lan Q, Rothman N, Purdue MP. 2011. Intra-individual variability over time in serum cytokine levels among participants in the prostate, lung, colorectal, and ovarian cancer screening Trial. Cytokine 56:145-8; doi:10.1016/j.cyto.2011.06.012.

Kelly RS, Lundh T, Porta M, Bergdahl IA, Palli D, Johansson A-S, et al. 2013. Blood erythrocyte concentrations of cadmium and lead and the risk of B-cell non-Hodgkin's lymphoma and multiple myeloma: a nested case-control study. PLoS One 8:e81892; doi:10.1371/journal.pone.0081892. 
Larsson N, Brown J, Stenfors N, Wilson S, Mudway IS, Pourazar J, et al. 2013. Airway inflammatory responses to diesel exhaust in allergic rhinitics. Inhal. Toxicol. 25:160-7; doi:10.3109/08958378.2013.765932.

Lauw FN, Hove T, Dekkers PEP, Jonge E De, Deventer SJH Van, Der T Van, et al. 2000. Production by Lymphocytes after In Vivo Exposure of Healthy Subjects to Endotoxin Reduced Th1, but Not Th2, Cytokine Production by Lymphocytes after In Vivo Exposure of Healthy Subjects to Endotoxin. 2-7; doi:10.1128/IAI.68.3.10141018.2000.Updated.

Liao W, Lin J-X, Leonard WJ. 2013. Interleukin-2 at the crossroads of effector responses, tolerance, and immunotherapy. Immunity 38:13-25; doi:10.1016/j.immuni.2013.01.004.

Lubin JH, Colt JS, Camann D, Davis S, Cerhan JR, Severson RK, et al. 2004. Epidemiologic evaluation of measurement data in the presence of detection limits. Environ. Health Perspect. 112: 1691-6.

McHale CM, Zhang L, Lan Q, Vermeulen R, Li G, Hubbard AE, et al. 2011. Global gene expression profiling of a population exposed to a range of benzene levels. Environ. Health Perspect. 119:628-34; doi:10.1289/ehp.1002546.

Morse D, Pischke SE, Zhou Z, Davis RJ, Flavell R a, Loop T, et al. 2003. Suppression of inflammatory cytokine production by carbon monoxide involves the JNK pathway and AP-1. J. Biol. Chem. 278:36993-8; doi:10.1074/jbc.M302942200.

Navarro SL, Brasky TM, Schwarz Y, Song X, Wang CY, Kristal AR, et al. 2012. Reliability of serum biomarkers of inflammation from repeated measures in healthy individuals. Cancer Epidemiol. Biomarkers Prev. 21:1167-70; doi:10.1158/1055-9965.EPI-12-0110.

Palli D, Berrino F, Vineis P, Tumino R, Panico S, Masala G, et al. 2003. A molecular epidemiology project on diet and cancer: the EPIC-Italy Prospective Study. Design and baseline characteristics of participants. Tumori 89: 586-93.

Panasevich S, Leander K, Rosenlund M, Ljungman P, Bellander T, de Faire U, et al. 2009. Associations of long- and short-term air pollution exposure with markers of inflammation and coagulation in a population sample. Occup. Environ. Med. 66:747-53; doi:10.1136/oem.2008.043471.

Rückerl R, Greven S, Ljungman P, Aalto P, Antoniades C, Bellander T, et al. 2007. Air pollution and inflammation (interleukin-6, C-reactive protein, fibrinogen) in myocardial infarction survivors. Environ. Health Perspect. 115:1072-80; doi:10.1289/ehp.10021.

Saberi Hosnijeh F, Boers D, Portengen L, Bueno-de-Mesquita HB, Heederik D, Vermeulen R. 2012. Plasma Cytokine Concentrations in Workers Exposed to 2,3,7,8tetrachlorodibenzo-p-dioxin (TCDD). Front. Oncol. 2:37; doi:10.3389/fonc.2012.00037.

Saberi Hosnijeh F, Krop EJM, Scoccianti C, Krogh V, Palli D, Panico S, et al. 2010. Plasma cytokines and future risk of non-Hodgkin lymphoma (NHL): a case-control study nested in the Italian European Prospective Investigation into Cancer and Nutrition. Cancer Epidemiol. Biomarkers Prev. 19:1577-84; doi:10.1158/1055-9965.EPI-09-1237. 
Seaton a, Soutar a, Crawford V, Elton R, McNerlan S, Cherrie J, et al. 1999. Particulate air pollution and the blood. Thorax 54: 1027-32.

Simoni M, Baldacci S, Maio S, Cerrai S, Sarno G, Viegi G. 2015. Adverse effects of outdoor pollution in the elderly. J. Thorac. Dis. 7:34-45; doi:10.3978/j.issn.20721439.2014.12.10.

Steenhof M, Mudway IS, Gosens I, Hoek G, Godri KJ, Kelly FJ, et al. 2013. Acute nasal proinflammatory response to air pollution depends on characteristics other than particle mass concentration or oxidative potential: the RAPTES project. Occup. Environ. Med. 70:341-8; doi:10.1136/oemed-2012-100993.

Trifunović J, Miller L, Debeljak Ž, Horvat V. 2015. Pathologic patterns of interleukin 10 expression-A review. Biochem. medica 36-48.

Tsai D-H, Amyai N, Marques-Vidal P, Wang J-L, Riediker M, Mooser V, et al. 2012. Effects of particulate matter on inflammatory markers in the general adult population. Part. Fibre Toxicol. 9:24; doi:10.1186/1743-8977-9-24.

Van Eeden SF, Tan WC, Suwa T, Mukae H, Terashima T, Fujii T, et al. 2001. Cytokines involved in the systemic inflammatory response induced by exposure to particulate matter air pollutants (PM(10)). Am. J. Respir. Crit. Care Med. 164:826-30; doi:10.1164/ajrccm.164.5.2010160.

Vossoughi M, Schikowski T, Vierkötter A, Sugiri D, Hoffmann B, Teichert T, et al. 2014. Air pollution and subclinical airway inflammation in the SALIA cohort study. Immun. Ageing 11:5; doi:10.1186/1742-4933-11-5.

Wang R, Henderson SB, Sbihi H, Allen RW, Brauer M. 2013. Temporal stability of land use regression models for traffic-related air pollution. Atmos. Environ. 64:312-319; doi:10.1016/j.atmosenv.2012.09.056.

Wong H-L, Pfeiffer RM, Fears TR, Vermeulen R, Ji S, Rabkin CS. 2008. Reproducibility and correlations of multiplex cytokine levels in asymptomatic persons. Cancer Epidemiol. Biomarkers Prev. 17:3450-6; doi:10.1158/1055-9965.EPI-08-0311.

Zarogoulidis P, Katsikogianni F, Tsiouda T, Sakkas A, Katsikogiannis N, Zarogoulidis K. 2014. Interleukin-8 and interleukin-17 for cancer. Cancer Invest. 32:197-205; doi:10.3109/07357907.2014.898156.

Zuurbier M, Hoek G. 2011. In-traffic air pollution exposure and CC16, blood coagulation, and inflammation markers in healthy adults. Environ. Heal. ... 1384: 1384-1389. 